\title{
Development of Smart Magnetic Braking Actuator Control for a Heavy Electric Vehicle
}

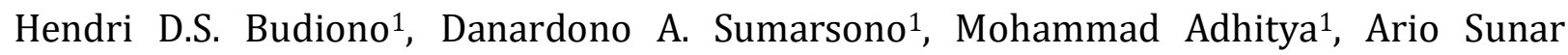
Baskoro ${ }^{1}$, Agung Shamsuddin Saragih ${ }^{1}$, Sonki Prasetya ${ }^{1,2 *}$, Fuad Zainuri1,2, Nazaruddin ${ }^{1}$, Ghany Heryana ${ }^{1}$, Rolan Siregar ${ }^{1}$

\author{
${ }^{1}$ Research Center for Advanced Vehicles (RCAVE), Faculty of Engineering, Universitas Indonesia, Kampus UI \\ Depok, Depok 16424, Indonesia \\ ${ }^{2}$ Department of Mechanical Engineering, Politeknik Negeri Jakarta, Kampus UI Depok, Depok 16425, \\ Indonesia
}

\begin{abstract}
A common heavy vehicle, such as a bus, has a drum brake system as its safety feature. This braking system utilizes air pressure inside pneumatic cylinders as an actuator for moving the braking cam in order to create friction between the brake shoe with the drum. Air pressure is produced by a compressor with the help of the internal combustion engine (ICE) rotational part. However, in the case of electric vehicles (EV), there is no rotational moving part on the engine when the vehicle stops. Furthermore, EVs use electric power as their fuel obtained from the battery. Thus, this study focuses on developing an alternative actuator for EV braking to substitute the air actuator system by the direct electric powered actuator system. By utilizing a magnetic system via a solenoid for moving the lever of the cam, the tests confirm that the implementation of the alternative actuator functionally works. The objective of this research is to obtain the proper control system in order to gradually generate the magnetic field. Additionally, the signal from the operator is then processed by an intelligent method-so-called fuzzy control-to produce a signal for the magnetic braking system comparable to the behavior of the pneumatic actuator. The results show that the intensity of braking can be alternated depending on the braking signal variation using $10 \mu$ s sampling period input pulse width modulation (PWMs) with 10 ms periods of execution time. Furthermore, this method improves the time response that compensates the delay due to piping-hoses in the pneumatic system.
\end{abstract}

Keywords: Electric actuator; Electric vehicles; Fuzzy; Magnetic

\section{Introduction}

A braking system is one of the most important features in a vehicle. Braking system can be categorized into hydraulic, electric, and mechanical brakes according to (Khurmi and Gupta, 2005). Trucks and buses are considered heavy vehicles that commonly use mechanical brakes in their drum brake design system (Bu and Tan, 2007). The mechanical brake utilizes an air force via a pneumatic actuator to produce linear movement. This action expands the brake shoe to create friction with the wheel drum in order to decelerate the vehicle.

${ }^{*}$ Corresponding author's email: sonki.prasetya@mesin.pnj.ac.id, Tel.: +62-21-87777640698 doi: 10.14716/ijtech.v11i7.4462 
Heavy vehicles provide air generated by a compressor stored in a tank. This compressor is powered by the rotating part of the internal combustion engine (ICE) (Holmberg et al., 2014). Currently, electric vehicles (EVs) have gained popularity due to their potential advantages such as more friendly to the environment and low total cost of ownership compared to conventional ICE vehicles (Sheth and Sarkar, 2019). Instead of ICE, EVs rely heavily on electric motors as their prime mover ( Riba et al., 2016; Eldho Aliasand and Josh, 2020).

However, electric buses that use conventional pneumatic actuators powered by compressors experience increased inefficiency and loss due to the applied conversion stages, namely the compressor, air tank, cylinders, hoses, etc. for braking events (Bendix, 2009). Additionally, the supporting components naturally contribute additional weight to a vehicle. Government regulation PP No 55/2012 states that buses can be categorized into several classes, such as small, medium, big, maxi, tandem, and double-decker, depending on their size and weight (GoI, 2012). Moreover, the rule restricts the allowed weight. For instance, a big bus class (12m or longer) can only have a maximum weight of 16 tons. Therefore, an alternative actuator uses electric power to produce linear movement with the advantage of reduction stages; the weight for braking is also investigated.

Numerous research articles have focused on EV areas, such as the research pertaining to air conditioners using brushless direct current (DC) compressors (Nasruddin and Sinambela, 2015). Particularly, for investigations regarding EV braking, a combinational regenerative and mechanical braking system is studied by (Yusivar et al., 2015). However, the study emphasized the control of combining friction and harnessing energy from the movement of the vehicle. Other types of so-called electric powered braking systems use the principle of electromagnetic force, which can be applied, for instance, in cranes and wheel chairs. Moreover, the electric braking system is also applied for a high-speed train in Germany (Hofmann et al., 2000; Yasa et al., 2016). This study utilizes a magnetic solenoid principle for the electric braking actuator. However, with on/off activation controls, activation results in the sudden movement of the vehicle. This presents a problem, as conventional pneumatic actuator braking systems have different responses to the solenoid system. It follows the rule of pressurized air, as shown in the research conducted by (Yang et al., 2017), and also generates transmission loses (Wang et al., 2017). In order to control the magnetic field to differentiate the breaking intensity, a controller is prepared to generate the signal to the magnetic solenoid. The research objective is to obtain a proper control for smooth braking action by using the magnetic actuator with the integration of an artificially intelligent (AI) method. Furthermore, AI control would improve the performance of the response time of the actuator.

\section{Methods}

Air brake systems for heavy vehicles use brake chambers, and there are two types of break chambers: a service-brake only chamber and a service-brake coupled with a parking brake chamber. The first chamber can be normally applied to the front wheels of the vehicle, while the second chamber can be applied to the rear wheels. The parking brake system is meant for the vehicle during parking/before driving. Therefore, it needs to be released first by adding pressurized air into the chamber via a park nozzle. Once the parking brake is released, the vehicle can be driven, and the service brake can be applied to slow or stop the vehicle once it is in motion.

The intelligent 'smart' control method application focuses on the service braking system. The investigated system replaces the pneumatic brake chamber into a solenoid module, which has a plunge that couples the slack-adjuster, as shown in Figure 1. Later on, 
the movement of the slack-adjuster, due to the pulling movement of the solenoids' activation, makes the brake-shoe expand. Thus, friction is generated to the wheel via the drum-brake.

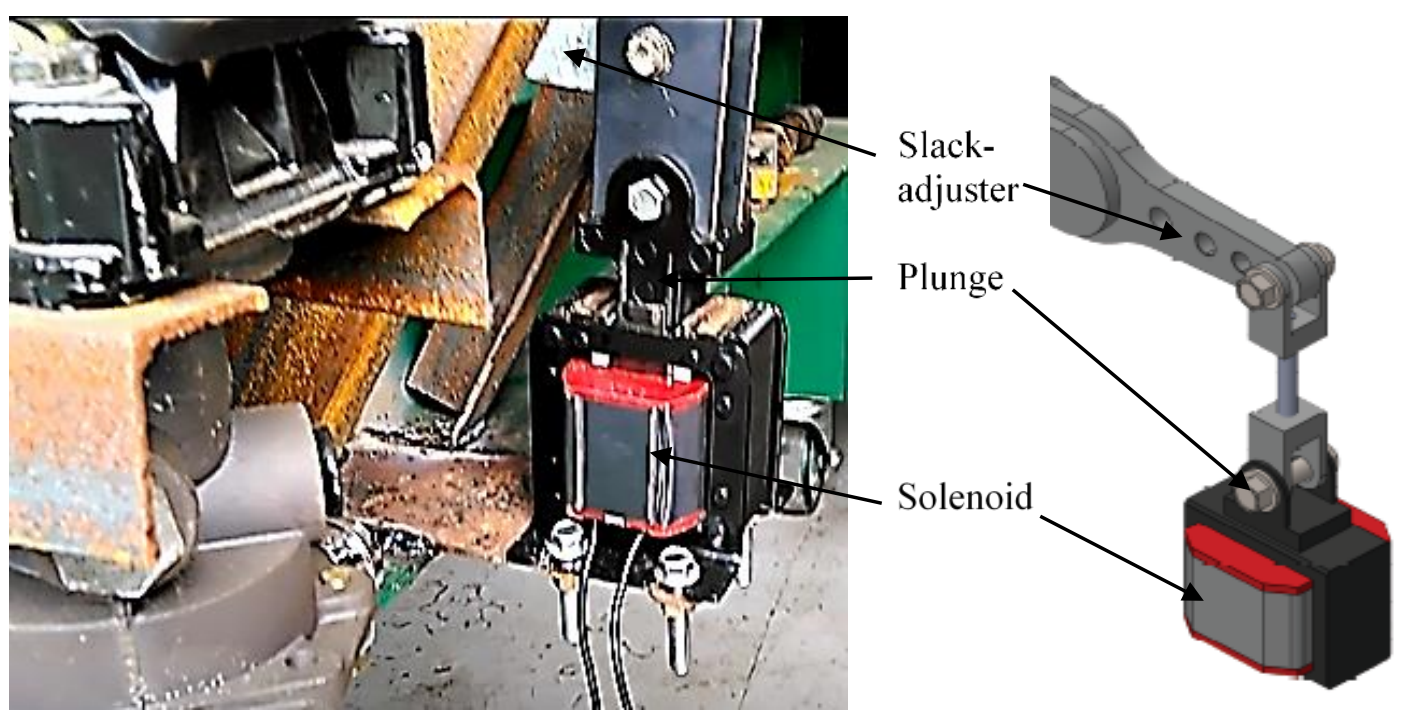

Figure 1 Solenoid brake arrangement

The alternative design of the braking actuator uses a magnetic principle, the formula of magnetic flux density $(B)$ in a toroidal coil, which is defined as (Ida, 2015):

$$
B=\frac{\mu_{0} I N}{A}[T]
$$

Furthermore, the electromagnetic lifting force $(F)$ can be calculated using the following formula:

$$
F=\frac{(I N)^{2} \mu_{0} A}{2 g^{2}}[N]
$$

where $N, I, \mu_{0}$ and $A$ represent the number of coil winding turns, the current $(A)$, the permeability of air (Tm/A)), and the area $\left(\mathrm{m}^{2}\right)$ of the poles, respectively. Furthermore, the direction between the magnetic flux density with the force follows Fleming's left hand rule.

A voltage equation $\left(V_{s o l}\right)$, by applying Kirchhoff's law, is used to control the generated magnetic flux density of the solenoid as the equivalent circuit. The solenoid voltage consists of the resistor $\left(V_{R}\right)$ and an inductor voltage $\left(V_{L}\right)$ (Badr, 2018; Taghizadeh et al., 2009), as follows:

$$
V_{\text {sol }}=V_{R}+V_{L}
$$

Therefore,

$$
V_{\text {sol }(t)}=R i_{(t)}+L \frac{d i_{(t)}}{d t}
$$

Substituting Equation 4 with Equations 1 or 2 implies that the voltage change will result in the variation of the current. Furthermore, the magnitude of the magnetic flux density will depend on the current flow to the solenoid conductor coil. Meanwhile, the current is generated once voltage signal from the controller applied to the conductor coil.

The solenoid response characteristic simulation, using a direct step input of $380 \mathrm{~V}_{\mathrm{AC}}$ to represent an emergency braking action signal, shows the rapidly generated current, as 
depicted in Figure 2. Thus, the brake will lock the wheel immediately and result in a slip condition. This, however, contradicts the response of the pneumatic actuator brake system, which experiences delays during emergency braking actions.
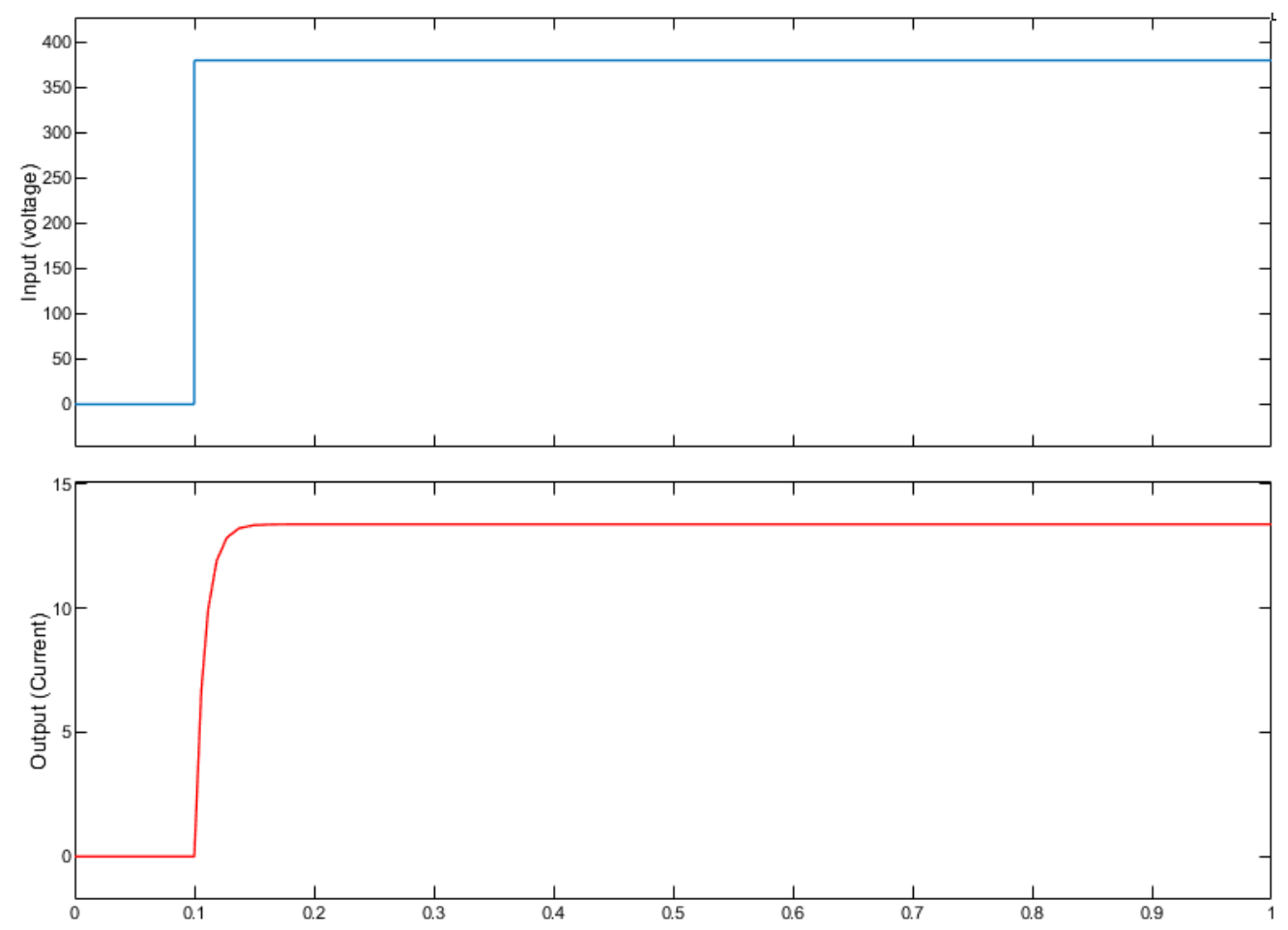

Figure 2 Solenoid response for voltage step input

The experiment of the pneumatic actuator by (Acarman et al., 2000) shows the delayed response of the pneumatic actuator, which is shown in Figure 3. It has a slightly delayed response when the pedal hit $0 \mathrm{~s}$. Furthermore, the rising time slowly increases at $0.4 \mathrm{~s}$ and settles after $0.7 \mathrm{~s}$. Therefore, the characteristic follows a polynomial function:

$$
\operatorname{Pres}_{(t)}=-185.31 t^{2}+305.95 t-6.0317 .
$$

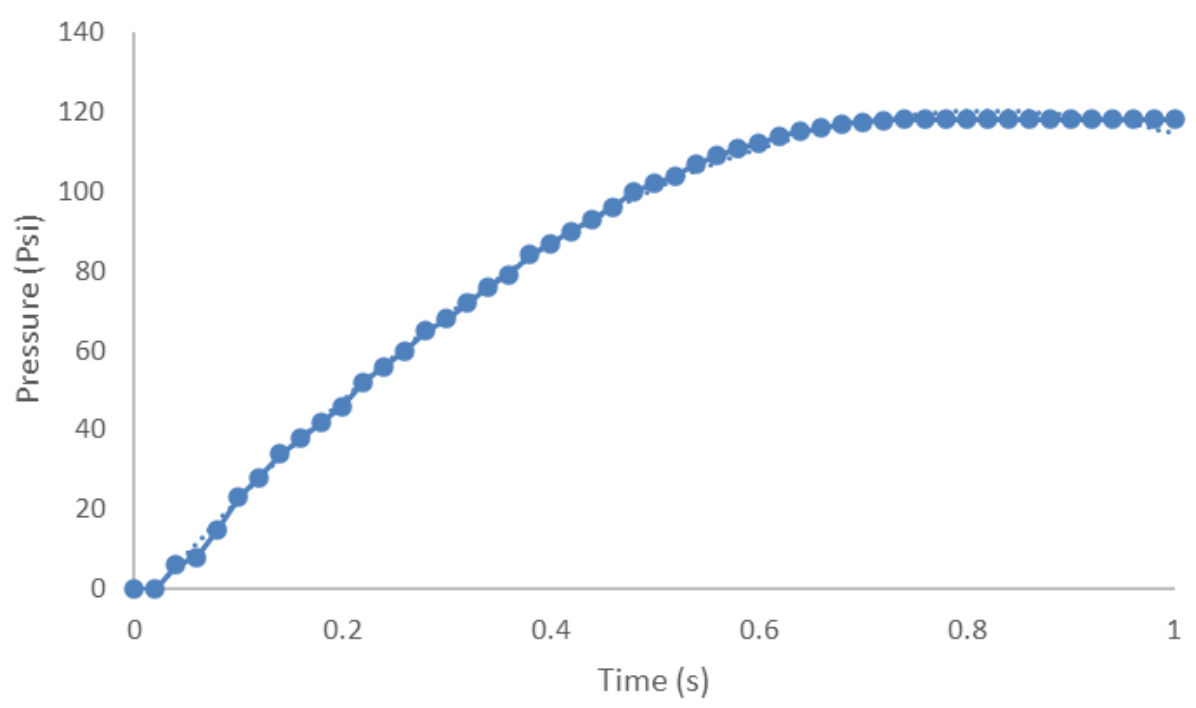

Figure 3 Pneumatic actuator response time

In order to create a characteristic of the pneumatic actuator, the electric actuator must be adjusted. The pneumatic braking cylinder supplies around $0.5 \mathrm{~ms}$ from its minimum to 
its maximum pressure due to piping transmission (Yang et al., 2017). The transfer function between the current (output) and the voltage (input) in the solenoid system (Sol) using modified Equation 4 adding to the ability to mimic the pneumatic response, as shown in the following equation.

$$
\text { Sol }=\frac{7.2}{(0.24 s+28.4)(1.2 s+7.2)} .
$$

Wang et al.'s (2017) experiment proves that transmission lines' piping-hose creates a total delay response of $30 \%$. This study observes the behavior of a solenoid system with the model of pneumatic characteristic response. Moreover, to improve the response due to the loss in piping, an intelligent method is integrated.

Several techniques integrating artificial intelligence (AI) have been analyzed regarding their implementation to the electrical machine, in addition to the various intelligent methods that have already been implemented by researchers. For machine optimization applications, some of these methods include particle swarm optimization (PSO), genetic algorithms (GAs), and fuzzy logic (Imad et al., 2019). The last method, fuzzy logic, is used in numerous applications for decision-making, such as energy consumption reduction for EVs (Kraa et al., 2014). Thus, this method is selected for creating artificial pneumatic response improvement for braking action.

Modern devices controlled by computers/controllers use the pulse width modulation (PWM) method by means of switching control. This is due to the digital signal, which is mostly utilized in computers/controllers. The basic principle is to manage how long the device needs to be turned "on" and "off" in a determined period; this period usually lasts less than a micro second, and most power electronics implement this method (Chang et al., 2019). There are three well-known PWM techniques: sinusoidal, space vector, and hysteresis PWM (Yu et al., 1997).

The electric brake actuator applies a solenoid design using coil winding, and its specification is determined using Equations 1 and 2. The simulation of the system uses the schematic presented in Figure 4 below.

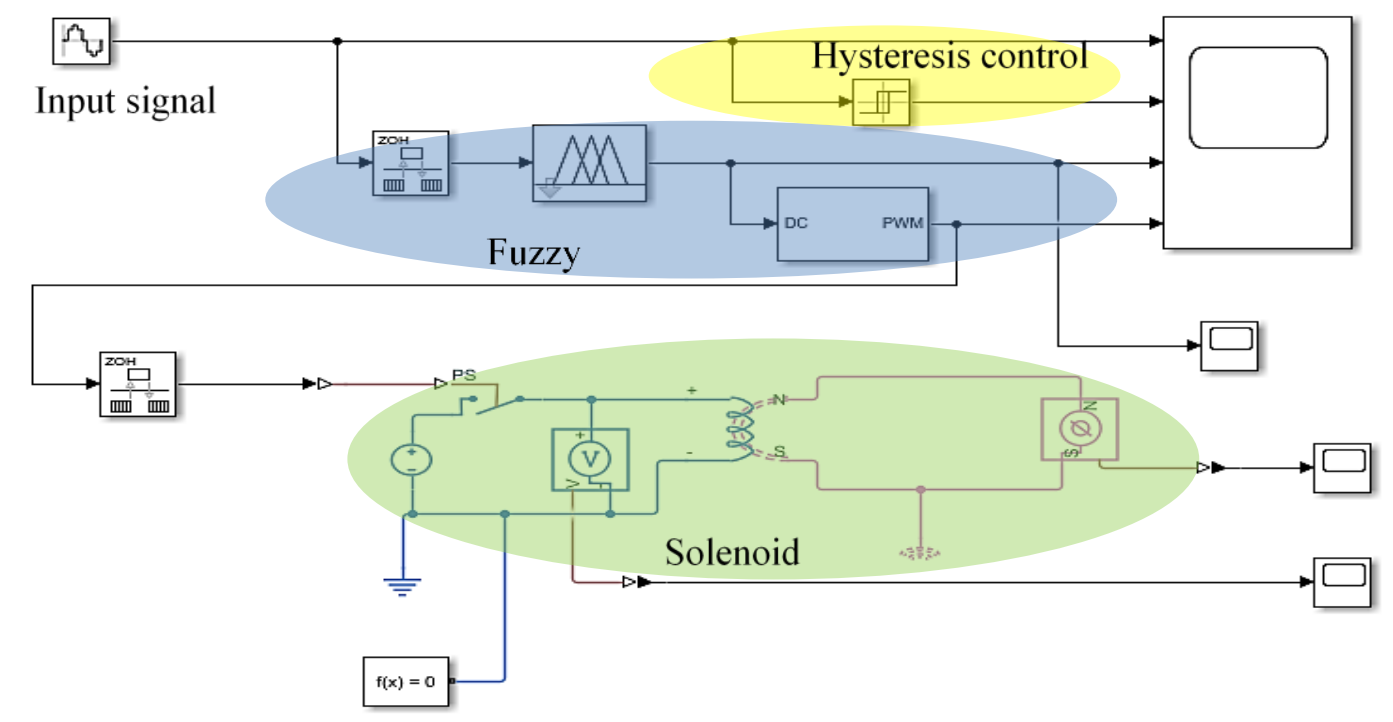

Figure 4 Schematic of the system

The simulation compares two main outcomes: direct-control on-off) using hysteresis inside yellow-coloured block and fuzzy control inside the blue-coloured block. Output of the fuzzy control block is fed to the actuator system inside the green-coloured block. The 
system uses a sampling period of one micro-second to mimic an analog signal system. However, the processor uses $10 \mu$ s sampling periods to consider for the time for calculating the decision. An input signal for braking is created to simulate the braking action in $1 \mathrm{~s}$ period. This system compares two results of signal responses. The first output signal comes from the direct control (yellow-coloured block) and only processes the input with a threshold (hysteresis) limiter. When a brake incident occurs (the brake-pedal is pushed), the intensity of the pushed brake-pedal is converted into value from 0 (minimum) to 1 (maximum). The value will change from 0 to 1 if the brake-pedal hits at least half of its maximum position. For the second output, the signal is derived from the fuzzy controller system, which undergoes three stages: fuzzification, fuzzy rules, and defuzzification. The fuzzy control signal outcome is then processed by the PWM generator using a similar sampling period and is fed to the actuator driver. Furthermore, it is connected to the driver system and to the solenoid actuator system (inside the green-coloured block), which is activated in a $1 \mathrm{~ms}$ period. However, this paper only covers the control system part.

The end process from the blue-coloured block shown in Figure 4 is then sampled every $1 \mathrm{~ms}$ for generating PWM signal. The PWM is used to switch the solid-state relay (SSR) to activate the solenoid depending on the duty cycle in a sampling period. This generates an electromagnetic force that acts as the push-rod to pull the slack-adjuster (see Figure 1). Thus, this movement rotates the cam to produce friction in the inner-side wall of the braking drum.

This dataset is then processed by the fuzzy logic controller to decide the braking actuator movement. The MATLAB Fuzzy toolbox is used for making braking decisions: whether no-brake, moderate-brake, or hard-brake with an amplitude from 0 to 1 . The membership function is sets of function shapes in fuzzy control stage to categorize the value into linguistic group. It consists of a linguistic value of the input variable universe and output variable universe, as shown in Figure 4. For the first variable, the function (pedal pushed [ $t$ ]) consists of three categories: not-pushed (NP), moderate-pushed (MP), and hard-pushed (HP), with a universe of discourse $(0,1)$. This means that the pushed pedal intensity value ranges from minimum $(0)$ to maximum (1). The output variable universe function (braking intensity [t]) also has three groups: no brake (NB), medium brake (MB), and hard-brake (HB), with intervals $(0,1)$.

The input variable universe uses triangular functions, while the output variable universe uses mixed triangular and trapezoidal functions to copy the behavior of the pneumatic actuator. The input category model of pedal hit intensity is generated using the following three equations:

$$
\begin{gathered}
\mu_{N P}(x)=\left\{\begin{array}{cl}
1, & x=0 \\
\frac{0.5-x}{0.5}, & 0 \leq x \leq 0.5
\end{array}\right\} \\
\mu_{M P}(x)=\left\{\begin{array}{cl}
\frac{x-0.5}{0.4}, & 0.1 \leq x \leq 0.5 \\
1, & x=0.5 \\
\frac{0.9-x}{0.4}, & 0.5 \leq x \leq 0.9
\end{array}\right\} \\
\mu_{H P}(x)=\left\{\begin{array}{cc}
\frac{x-1}{0.5}, & 0 \leq x \leq 0.5 \\
1, & x=1
\end{array}\right\}
\end{gathered}
$$

Additionally, the output model category consists of three shapes that were built by the following three equations: 


$$
\begin{gathered}
\mu_{N B}(x)=\left\{\begin{array}{cl}
1, & x=0 \\
\frac{0.7-x}{0.7}, & 0 \leq x \leq 0.7
\end{array}\right\} \\
\mu_{M B}(x)=\left\{\begin{array}{cl}
\frac{x-0.3}{0.2}, & 0.3 \leq x \leq 0.5 \\
1, & x=0.5 \\
\frac{0.7-x}{0.2}, & 0.5 \leq x \leq 0.7
\end{array}\right\} \\
\mu_{H B}(x)=\left\{\begin{array}{cl}
\frac{x-1}{0.5}, & 0.3 \leq x \leq 0.9 \\
1, & 0.9 \leq x \leq 1
\end{array}\right\}
\end{gathered}
$$

The representation of the function is shown in Figure 5. Figure 5a represents the graph of input, while the output function is represented in Figure $5 \mathrm{~b}$.

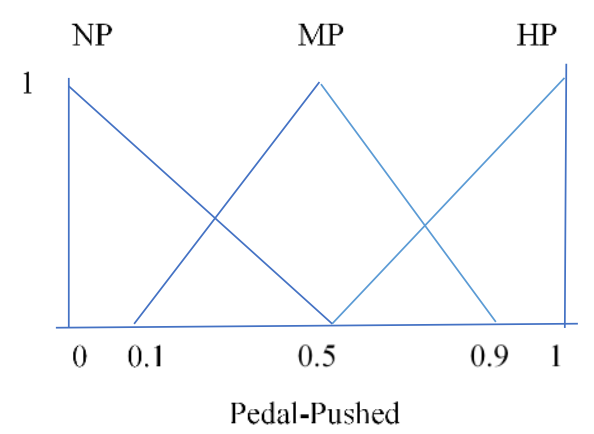

(a)

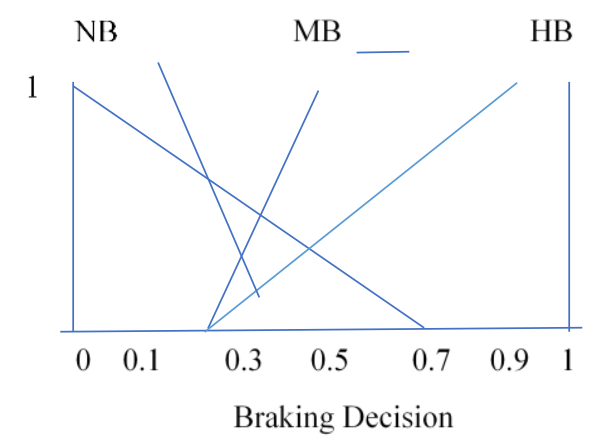

(b)

Figure 5 Membership function of input (a) and output (b)

The knowledge base is another stage of fuzzy control system that is intended to find the connection between the favored input and outputs. This is obtained via a lookup table to reflect the relationship of input and outputs via the Mamdani technique. Three rules are applied for any input crisp during the process.

If input is NP, then output is NB.

If input is MP, then output is MB.

If input is HP, then output is HB.

The output decision uses a centroid method to obtain the value, as shown in Figure 6.

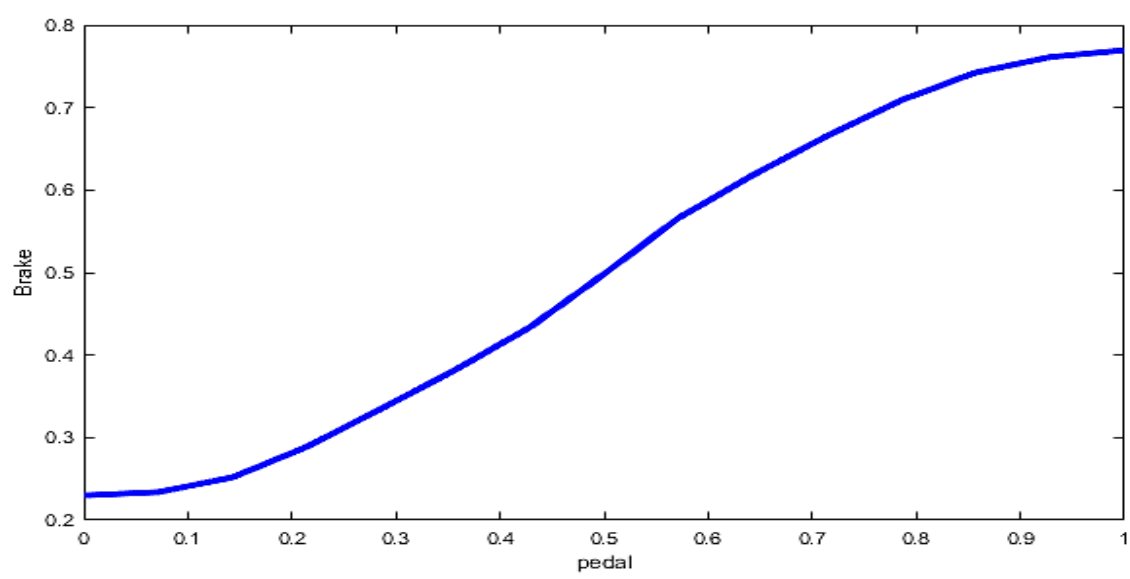

Figure 6 Response of pedal activation and braking intensity 
It plots the relationship between pedal hit and the brake intensity value, and this is presented by the duration of one second. The rise time can be adjusted depending on the requirement. However, the graph in Figure 6 shows that the trend rises higher in $0.3 \mathrm{~s}$ to 0.6s. Later, in Figure 7, the graph will be adjusted to show moderate increments.

\section{Results and Discussion}

The braking decision is presented in Figure 7. Input is created using the transfer function (Equation 6) via the MATLAB environment. It is processed and compared in the parallel graphs in four rows. The first row on the top shows the input signal simulating the pneumatic behavior response, which is artificially generated. This signal is used as input for both conventional (direct on-off) control and fuzzy control. The first given input reflects the intensity of the pedal from the low hit to its maximum hit and back to the low.

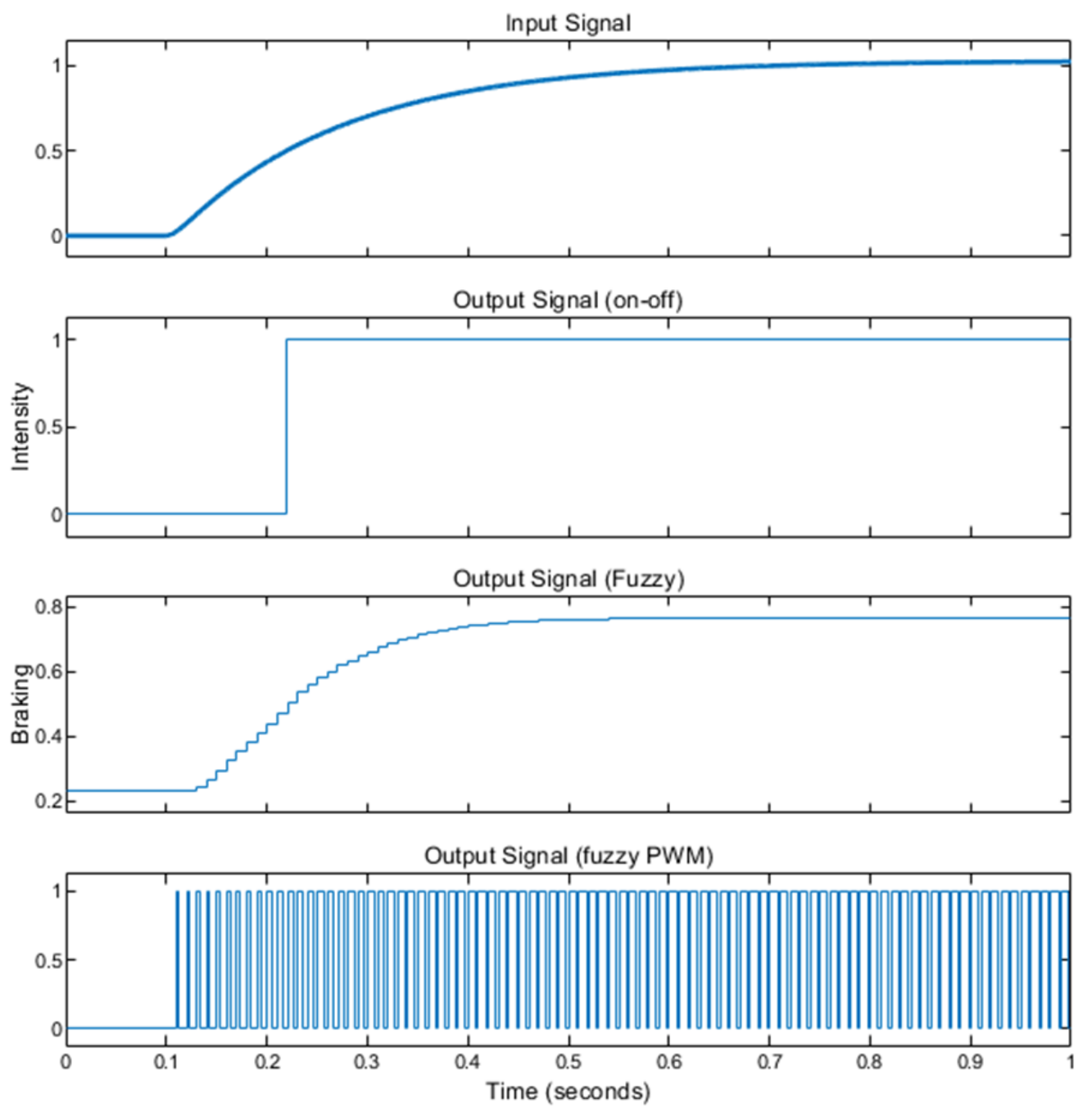

Figure 7 Signal comparison result

The second row shows the result of the electric signal when braking under on-off conditions using the threshold value (set at half of the maximum brake-pedal movement). The curve represents the digital mode "off" before the pedal is pushed at $50 \%$ and on afterward. Suppose this is applied to the vehicle, and it produces an immediate stop action. The graph in the third row, on the other hand, applies gradual braking steps due to fuzzy control. The period of decision is built every $1 \mathrm{~ms}$; therefore, step forms are seen in the 
graph. It is noticed that at the beginning of braking, a delay of $0.03 \mathrm{~s}$ appears. However, the rise-time slope of the fuzzy control shows rapid movement during $0.13 \mathrm{~s}$ to $0.3 \mathrm{~s}$. This is higher compared to the original signal. Thus, it improves the response time consumed by piping in a pneumatic actuator system.

The result of the braking signal with its intensity information cannot be applied directly to the solenoid driver. It must be manipulated first via a PWM signal converter. The implementation of this step's movement utilizes the PWM signal to the driver as generated in the last row. Thus, the response of imitating the pneumatic action with an improvement response is achieved.

The control of the electric braking actuator is different with the pneumatic braking actuator. This is due to the pressure response of pneumatic has certain delays for transmitting the air through nozzles and pipes during the braking action. However, the proposed solution has higher flexibility to be controlled. The electric actuator can be manipulated to have the analogous acting response as the pneumatic actuator system. The pneumatic response in Figure 3 can be implanted into the controller to make the electric actuator behaves similarly as seen on the first row of Figure 7. However, without action control by means of simple digital electric control method ('on-off'), it reacts too quick. Thus, it is prevented to be used for braking application.

The signal is sampled in $1 \mathrm{~ms}$ period makes the curve has steps shape due to the PWM technique. However, the direct PWM application to the input signal (the first row of this figure) will also generate delays. Fuzzy control addition to the controller improves the response of the input from the system model. Although it reacts slowly at the beginning, it rises up quickly to achieve the steady-state condition during stop braking incident. This reduces the delay from the origin input signal. Therefore it minimizes the transmission delay problem as stated in (Wang et al., 2017).

\section{Conclusions}

A model of an electric braking actuator is developed to have the analogous response to the pneumatic braking actuator. Integrating AI method, namely the fuzzy logic control, was applied to generate braking signals to provide smoother curves (similar to the conventional pneumatic actuator response). Thus, abrupt deceleration is prevented using a mixed shape for function. Moreover, the fuzzy controller can improve the time response result and minimize the $30 \%$ loss due to the piping-hose in the pneumatic system. In order to implement the results of the braking intensity, the PWM technique manipulates the outcome of the fuzzy controller and uses a sampling period of $1 \mathrm{~ms}$ to process the signal, which is dedicated to digitally controlling the magnetic field and pushing the rod for braking action.

\section{Acknowledgements}

The work of this research was supported by Penelitian Terapan Unggulan Perguruan Tinggi (PTUPT NKB-2949/UN2.RST/HKKP.05.00/2020) of Ristekdikti and Publikasi Unggulan Terindeks Internasional (PUTI NKB-645/UN2.RST/HKP.05.00/2020) Research Grants. Many thanks for all parties at the Universitas Indonesia and Politeknik Negeri Jakarta, which provided facilities and opportunities to this study. 


\section{References}

Acarman, T., Ozguner, U., Hatipoglu, C., Igusky, A.-M., 2000. Pneumatic Brake System Modeling for System Analysis. In: Paper presented at the Truck and Bus Meeting and Exposition, Portland

Badr, M.F., 2018. Modelling and Simulation of a Controlled Solenoid. In: IOP Conference Series: Materials Science and Engineering, 433, 012082. doi:10.1088/1757899x/433/1/012082

Bendix., 2009. Air Brake Handbook. Ohio, USA: Bendix Commercial Vehicle Systems LLC

$\mathrm{Bu}, \mathrm{F} ., \mathrm{Tan}, \mathrm{H} ., 2$ 2007. Pneumatic Brake Control for Precision Stopping of Heavy-Duty Vehicles. IEEE Transactions on Control Systems Technology, Volume 15(1), pp. 53-64

Chang, E.-C., Liu, Y.-C., Chang, C.-H., 2019. Experimental Performance Comparison of Various Sliding Modes Controlled PWM Inverters. Energy Procedia, Volume 156, pp. 110-114

Eldho Aliasand, A., Josh, F.T., 2020. Selection of Motor foran Electric Vehicle: A Review. Materials Today: Proceedings, Volume 24, pp. 1804-1815

GoI (Government of Indonesia), 2012. Peraturan Pemerintah No 55 tentang Kendaraan (

Government Regulations No. 55 about Vehicle)

Hofmann, M., Werle, T., Pfeiffer, R., Binder, A., 2000. 2D and 3D Numerical Field Computation of Eddy-current Brakes for Traction. IEEE Transactions on Magnetics, Volume 36(4), pp. 1758-1763

Holmberg, K., Andersson, P., Nylund, N.-O., Mäkelä, K., Erdemir, A., 2014. Global Energy Consumption due to Friction in Trucks and Buses. Tribology International, Volume 78, pp. 94-114

Ida, N., 2015. Engineering Electromagnetics (3 ${ }^{\text {rd }}$ ed.): Springer

Imad, M., Hosseini, A., Kishawy, H.A., 2019. Optimization Methodologies in Intelligent Machining Systems - A Review. IFAC-PapersOnLine, Volume 52(10), pp. 282-287

Khurmi, R., Gupta, J., 2005. A Textbook of Machine Design: S Chand \& Co Ltd

Kraa, O., Becherif, M., Ayad, M.Y., Saadi, R., Bahri, M., Aboubou, A., Tegani, I., 2014. A Novel Adaptive Operation Mode based on Fuzzy Logic Control of Electrical Vehicle. Energy Procedia, Volume 50, pp. 194-201

Nasruddin, N., Sinambela, H., 2015. Design and Experimental Study of Air Conditioning System using Brushless Direct Current (BLDC) Compressor in National Electric Car. International Journal of Technology, Volume 6(6), pp. 954-960

Riba, J.-R., López-Torres, C., Romeral, L., Garcia, A., 2016. Rare-earth-free Propulsion Motors for Electric Vehicles: A Technology Review. Renewable and Sustainable Energy Reviews, Volume 57, pp. 367-379

Sheth, A., Sarkar, D., 2019. Life Cycle Cost Analysis for Electric vs. Diesel Bus Transit in an Indian Scenario. International Journal of Technology, Volume 10(1), pp. 105-115

Taghizadeh, M., Ghaffari, A., Najafi, F., 2009. Modeling and Identification of a Solenoid Valve for PWM Control Applications. Comptes Rendus Mécanique, Volume 337(3), pp. 131140

Wang, Z., Zhou, X., Yang, C., Chen, Z., Wu, X., 2017. An Experimental Study on Hysteresis Characteristics of a Pneumatic Braking System for Muli-Axle Heavy Vehicle in Emergency Braking Situations. Applied Sciences, Volume 7(8), pp. 1-17

Yang, F., Li, G., Hua, J., Li, X., Kagawa, T., 2017. A New Method for Analysing the Pressure Response Delay in Pneumatic Brake System Caused by the Influence of Transmission Pipes. Applied Sciences, Volume 7(9), pp. 1-20

Yasa, Y., Sincar, E., Ertugrul, B.T., Mese, E.. 2016. A Multidisciplinary Design Approach for Electromagnetic Brakes. Electric Power Systems Research, Volume 141, pp. 165-178 
Yu, Z., Mohammed, A., Panahi, I., 1997. A review of three PWM techniques. In: Proceedings of the 1997 American Control Conference (Cat. No.97CH36041)

Yusivar, F., Haslim, H.S., Farabi, Y., Nuryadi, K., 2015. New Control Scheme for Combined Regenerative and Mechanical Brakes in Electric Vehicles. International Journal of Technology, Volume 6(1), pp. 44-52 